\title{
DESENVOLVIMENTO DE PROCESSO DE PRODUÇÃO DE CONJUNTOS ELETRODO-MEMBRANA-ELETRODO PARA CÉLULAS A COMBUSTÍVEL BASEADAS NO USO DE MEMBRANA POLIMÉRICA CONDUTORA DE PRÓTONS (PEMFC) POR IMPRESSÃO A TELA
}

\author{
Rafael Nogueira Bonifácio* e Marcelo Linardi \\ Instituto de Pesquisas Energéticas e Nucleares, Av. Lineu Prestes, 2242, 05508-000 São Paulo - SP, Brasil \\ Ricardo Cuenca \\ Faculdade de Tecnologia Gráfica Theobaldo de Nigriz, Serviço Nacional da Indústria, \\ Rua Bresser, 2315, 03162-030 São Paulo - SP, Brasil \\ Recebido em 12/3/10; aceito em 26/7/10; publicado na web em 16/11/10
}

\begin{abstract}
DEVELOPMENT OF A SIEVE PRINTING PROCESS FOR THE PRODUCTION OF MEMBRANE ELECTRODE ASSEMBLY FOR PROTON EXCHANGE MEMBRANE FUEL CELL. Proton exchange membrane fuel cell (PEMFC) requires membrane electrode assemblies (MEA) to generate electrical energy from hydrogen and oxygen. In this study a MEA production process by sieve printing and an ink composition were developed to produce catalyst layers of MEAs. The deposition of the exact catalyst content was possible on cathodes and anodes with only one print step. The optimal ink developed shown viscosity of $2.75 \mathrm{~Pa} \mathrm{~s}$, density $1.27 \mathrm{~g}$ $\mathrm{cm}^{-3}$, total solid content of $33.76 \%$ and tack of 92 U.T. The electrodes prepared in only one printing step showed higher performance than those prepared in several steps.
\end{abstract}

Keywords: membrane electrode assembly; catalytic layer; ink composition.

\section{INTRODUÇÃO}

A demanda mundial de energia é uma tendência historicamente crescente e irreversível, por diversos fatores, dentre eles pode-se citar o aumento da população, que vem ocorrendo a altas taxas. Segundo projeções, a população mundial deve ultrapassar 9,2 bilhões de pessoas até 2050, o que corresponde a um aumento populacional de $43 \%$ em relação a 2007. ${ }^{1}$ Também segundo projeções, em 2080 o hidrogênio será a principal fonte de geração de energia do mundo, sendo então responsável por aproximadamente $90 \%$ da matriz energética. ${ }^{2}$ Diante dessas projeções, o desenvolvimento de sistemas capazes de gerar energia elétrica a partir do hidrogênio passa a ser uma necessidade estratégica para garantir o atendimento às demandas energéticas dos próximos anos. ${ }^{2,3}$

Células a combustível são dispositivos capazes de converter energia química em elétrica e térmica de forma direta, gerando corrente contínua por meio do suprimento de combustível e oxidante. ${ }^{4}$ Dentre os diversos tipos de células a combustível existentes, as que usam uma membrana polimérica condutora de prótons (PEMFC) como eletrólito têm características que tornam seu uso viável tanto para geração estacionária de energia elétrica, quanto para aplicações portáteis e, até mesmo, automotivas (com uso de um motor elétrico). ${ }^{2,4,5}$

Em um sistema de célula a combustível do tipo PEMFC, suprido com hidrogênio e oxigênio são conduzidas duas reações eletroquímicas parciais, em dois eletrodos separados por um eletrólito polimérico, formando água como produto da reação global e gerando energia elétrica e térmica com alta eficiência. As reações parciais e a reação global para hidrogênio e oxigênio são indicadas nas Equações 1, 2 e 3:3,6

$$
\begin{gathered}
\text { Ânodo: } \mathrm{H}_{2}+2 \mathrm{H}_{2} \mathrm{O} \rightarrow 2 \mathrm{H}_{3} \mathrm{O}^{+}+2 \mathrm{e}^{-} \\
\text {Cátodo: } 1 / 2 \mathrm{O}_{2}+2 \mathrm{H}_{3} \mathrm{O}^{+}+2 \mathrm{e}^{-} \rightarrow 3 \mathrm{H}_{2} \mathrm{O} \\
\text { Reação global: } \mathrm{H}_{2}+1 / 2 \mathrm{O}_{2} \rightarrow \mathrm{H}_{2} \mathrm{O}
\end{gathered}
$$

\footnotetext{
*e-mail: rbonifacio@ipen.br
}

Nessas reações o hidrogênio é oxidado no ânodo, os elétrons são conduzidos ao cátodo por um circuito externo, gerando corrente elétrica e os prótons são conduzidos ao cátodo através da membrana polimérica hidratada. ${ }^{5,7,8}$ No cátodo ocorre a redução do oxidante na presença dos prótons e elétrons provenientes do ânodo, formando moléculas de água e fechando o circuito elétrico., ${ }^{4,5}$

A estrutura onde as reações de uma PEMFC ocorrem é o conjunto eletrodo-membrana-eletrodo (MEA) - membrane electrode assembly. Esse conjunto é composto por uma membrana polimérica ${ }^{5,7,8}$ faceada por dois eletrodos de difusão gasosa (cátodo e ânodo), os quais são compostos por uma camada catalisadora e por uma camada difusora de gases - gas diffusion layer (GDL). ${ }^{4-6}$ A Figura 1 ilustra o funcionamento de uma PEMFC quando abastecida com hidrogênio e oxigênio.

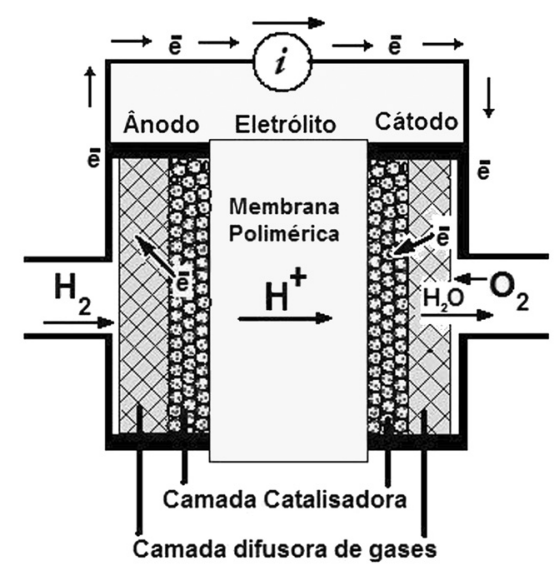

Figura 1. Ilustração de uma PEMFC em uso, quando abastecida com hidrogênio e oxigênio

A camada catalisadora é formada por uma estrutura complexa de sítios catalíticos, material condutor de prótons e poros, ou seja, uma mistura de eletrocatalisador (material formado por nanopartículas 
de metais nobres depositadas em um material suporte, geralmente de carbono) e ionômeros (polímeros de baixo peso molecular) do material da membrana, com vazios para a permeação dos reagentes e escoamento dos produtos da reação. Neste trabalho foram utilizados membrana e ionômero de Nafion ${ }^{\circledR} \cdot{ }^{7,8} \mathrm{O}$ eletrocatalisador tem a função de acelerar as reações de oxidação e redução que ocorrem no ânodo e cátodo, respectivamente. Os ionômeros de Nafion ${ }^{\circledR}$ têm a função de conduzir os prótons formados nos sítios ativos do eletrocatalisador até a membrana, de modo a proporcionar um aproveitamento máximo da reação anódica para a geração de corrente elétrica. ${ }^{4,6}$

A camada difusora de gases (GDL) tem a função de permitir a permeação de gases através de sua estrutura, distribuindo-os, de modo uniforme sobre a camada catalisadora. A GDL também tem a função de conduzir os elétrons envolvidos na reação da camada catalisadora do ânodo para o circuito externo, de onde esses elétrons se deslocam até o cátodo, sendo então conduzidos para a camada catalisadora do cátodo, onde a reação global é concluída. .,6,10 $^{4}$

O preparo de MEAs por diversas técnicas vem sendo objeto de estudo; diversas formulações de uma tinta precursora da camada catalisadora (TPCC) e vários processos de aplicação vêm sendo pesquisados. ${ }^{9-14}$ Trabalhos recentes compararam processos de deposição da camada catalisadora por pulverização (spray) e por impressão a tela, depositando a massa equivalente a $0,6 \mathrm{mg} \mathrm{Pt} \mathrm{cm}^{-2} \mathrm{em}$ cátodos e $0,4 \mathrm{mg} \mathrm{Pt} \mathrm{cm}^{-2}$ em ânodos, verificando que o desempenho final dos MEAs preparados por impressão a tela é superior. ${ }^{9}$

O preparo de uma tinta precursora da camada catalisadora (TPCC) consiste na dispersão dos constituintes da camada catalisadora em um veículo adequado (solvente, mistura de solventes, ou mistura de solventes e resinas). Sendo que, além dos requisitos de condutividade eletrônica e protônica que a camada catalisadora de uma PEMFC deve atender, é desejado que a TPCC apresente facilidade de aplicação, estabilidade ao longo do tempo, proporcione depósitos uniformes e que o veículo seja totalmente eliminado após aplicação. Assim, na formulação de um veículo para o preparo de uma TPCC, o uso de solventes é preferível ao uso de uma mistura de solventes e resinas. ${ }^{4,9-11,15}$

A função dos solventes em uma tinta é envolver os sólidos e mantê-los dispersos, permitindo sua aplicação por meio dos diversos processos existentes. ${ }^{16}$ De modo que, dentre os componentes de uma tinta, os solventes são os primeiros a entrar em contato com a superfície na qual a tinta é aplicada. Assim, a tensão superficial de um solvente, ou de uma mistura de solventes, determina a tensão superficial de uma tinta. A correta tensão superficial de uma tinta evita problemas de umectação e adesão, ${ }^{17}$ sendo necessário que essa tensão superficial seja menor que a do substrato de impressão ao qual será aplicada, para que não ocorram falhas na camada aplicada, ou até mesmo a impossibilidade de aplicação da tinta. ${ }^{16}$

Quando líquidos com diferentes tensões superficiais são misturados, a tensão superficial resultante, ou que prevalece, geralmente, é a menor, porque a superfície fica enriquecida com maior quantidade do líquido que tem a menor tensão superficial. A tensão superficial de líquidos é determinada de forma direta, existindo tensiômetros apropriados para os diversos sistemas líquidos possíveis. No caso dos sólidos (substratos de impressão) a medida de tensão superficial pode ser feita indiretamente, por meio do preparo de soluções com diversas concentrações do sólido diluído, determinando-se a tensão superficial das soluções e fazendo-se uma extrapolação do valor para $100 \%$ de sólidos, ou ainda, aplicando-se diversas soluções com tensões superficiais progressivamente maiores no material sólido e verificando com qual delas ocorre uma transição de comportamento em molhar e não molhar o sólido, sendo essa a tensão superficial do sólido. ${ }^{16}$

Em função da pressão de vapor, um solvente apresenta maior ou menor volatilidade a uma determinada temperatura, o que resulta no tempo de secagem por evaporação de uma tinta que o utilize. Quanto menor a pressão de vapor, menos volátil é um solvente e maior o seu tempo de secagem por evaporação. ${ }^{16} \mathrm{Na}$ Tabela 1 é apresentada a pressão de vapor de alguns solventes. ${ }^{17}$

Tabela 1. Pressão de vapor de alguns solventes

\begin{tabular}{cc}
\hline Solventes & Pressão de vapor $\left(\mathrm{mmHg}\right.$ a $\left.20^{\circ} \mathrm{C}\right)$ \\
\hline Etileno glicol & 0,08 \\
1-Heptanol & 0,50 \\
2-Propanol & 33,0 \\
Etanol & 44,6 \\
Metanol & 96,0 \\
\hline
\end{tabular}

Fonte: ref. 17

O teor de sólidos em massa determina o percentual de elementos sólidos não voláteis presentes na tinta, os quais permanecem após sua secagem. Analogamente, o teor de solventes em massa determina a quantidade de material volátil que será retirado da tinta no processo de secagem, devendo ambos ser controlados ao final do processo de preparo da tinta e corrigidos, caso seja necessário. ${ }^{16} \mathrm{O}$ máximo teor de sólidos possível em uma tinta é determinado por meio da concentração volumétrica crítica de partículas (CVCP), que é a concentração máxima de partículas sólidas em meio ao veículo (resinas + solventes), na qual o veículo consegue preencher todos os vazios em volta das partículas. Abaixo dessa concentração ocorre uma mudança no comportamento da mistura, passando a haver excesso de veículo, o que confere à tinta características que permitem sua aplicação por processos de impressão. ${ }^{16}$ Além dos teores de sólidos e de solventes, uma tinta pode ser caracterizada em função de propriedades como densidade, viscosidade e tack. ${ }^{16,18}$

Quando uma tinta com adequada tensão superficial é aplicada a uma superfície existe uma aderência à superfície, a qual não pode ser confundida com o tack. A aderência é resultado da interação da superfície do filme de tinta com a superfície que recebeu sua aplicação, enquanto o tack é a resistência que as camadas (internas) de um fluido úmido oferecem em se separar quando o fluido entra em contato com outra superfície. Sendo o tack, portanto, uma característica interna da tinta, resultante de interações físico-químicas decorrentes da composição da tinta e de seu processamento, fatores esses influenciados pelos sólidos e solventes utilizados e por suas concentrações, além da temperatura e pressão ambiente. A determinação do tack é feita por uma relação entre forças, na qual a força de coesão interna das moléculas do fluido atua em oposição à força exercida para separar as camadas de tinta, o que resulta em uma grandeza adimensional. ${ }^{18}$

Na avaliação de MEAs, são estudados potenciais desde o potencial de circuito aberto, em torno de $1 \mathrm{~V}$ até 0 (zero), ou um potencial considerado adequado aos dispositivos utilizados, uma vez que baixos potenciais exigem maiores densidades de corrente e que potenciais entre $0,5 \mathrm{e}$ 0,7 V são utilizados nas aplicações práticas, em função da boa relação entre potência e durabilidade que proporcionam aos MEAs. A faixa de potencial utilizada na avaliação do MEA foi entre 1,0 e 0,3 V.,19-21

Neste estudo foi formulada uma TPCC para aplicação sobre GDL, considerando os parâmetros apresentados e foi desenvolvido um processo de aplicação da TPCC por impressão a tela, permitindo o preparo de eletrodos de difusão gasosa para uso na confecção de MEAs para PEMFC.

\section{PARTE EXPERIMENTAL}

A tinta precursora da camada catalisadora foi preparada calculando-se a massa de sólidos a depositar por centímetro quadrado de 
eletrodo, tendo por base a aplicação de $0,4 \mathrm{mg} \mathrm{Pt} \mathrm{cm}^{-2}$ nos ânodos e $0,6 \mathrm{mg} \mathrm{Pt} \mathrm{cm}^{-2}$ nos cátodos dos eletrodos. Foi utilizado o eletrocatalisador de platina suportado em carbono (Pt/C) da BASF, o qual possui $20 \%$ em massa de platina. Foi calculada a massa de sólidos a depositar respeitando-se a proporção $65: 35^{5}$ entre eletrocatalisador e ionômero de Nafion, resultando em $2 \mathrm{mg}$ de eletrocatalisador e $1,077 \mathrm{mg}$ de ionômeros de Nafion por $\mathrm{cm}^{2}$.

A partir do diâmetro dos fios e da lineatura, ou número de fios por centímetro linear $\left(1 \mathrm{~cm}^{-1}\right)$, foi calculado o volume livre entre os fios formadores da trama dos diversos tecidos disponíveis comercialmente para o preparo da matriz de impressão a tela, os quais são informados em $\mathrm{BCM} \mathrm{cm}$ cm $^{-2}$ (bilhão de micrômetros cúbicos por centímetro quadrado).

O teor de sólidos e a densidade da solução de Nafion SE10072 foram determinados pela relação entre massas antes e após secagem e entre massa e volume conhecidos, respectivamente; com essas informações foi calculada, por extrapolação linear, a densidade teórica do ionômero de Nafion. Também foi calculada a densidade teórica do eletrocatalisador $\mathrm{Pt} / \mathrm{C}$ da BASF, por meio da média ponderada entre as massas e as densidades da platina e do carbono Vulcan XC72 presentes no eletrocatalisador. A seguir, as massas desses componentes a serem adicionadas por $\mathrm{cm}^{2}$ de eletrodo foram convertidas em volume por meio das respectivas densidades e subtraídas do volume da matriz de impressão, resultando no volume de veículo a ser adicionado para o preparo da TPCC.

Para uso como veículo da TPCC buscou-se uma mistura de solventes capaz de manter todos os componentes da tinta homogeneamente dispersos, que não evaporasse à temperatura ambiente por ter baixa pressão de vapor e fosse facilmente removida dos eletrodos por um processo de secagem a quente. A determinação da tensão superficial de solventes e do tecido de carbono foi feita com uso do tensiômetro Kruss K8551 (método do anel). Após experimentos prévios usando apenas etileno glicol como veículo, foi verificada a necessidade de ajuste da tensão superficial deste, o que foi feito satisfatoriamente com a adição de 5\% de 1-heptanol ao etileno glicol. Assim, a TPCC foi preparada com esse solvente, com ionômero de Nafion ${ }^{\circledR}$ proveniente da solução SE10072 da DuPont ${ }^{\circledR}$ e com eletrocatalisador $\mathrm{Pt} / \mathrm{C}$. Esses produtos misturados em um béquer foram dispersos a 12.000 e a $3.000 \mathrm{rpm}$ por períodos de 15 min e, então, a dispersão foi submetida a aquecimento e agitação magnética até a retirada dos solventes da solução de Nafion por evaporação, o que resultou na tinta pronta para impressão.

A tinta foi aplicada sobre a camada difusora de gases utilizada, Electrode Backing (EC-CC1-060T, da ElectroChem), por impressão a tela. O MEA com eletrodos de $25 \mathrm{~cm}^{2}$ foi preparado por prensagem a quente ${ }^{5}$ dos eletrodos em ambos os lados de uma membrana Nafion $115^{\circledR}$, da Dupont ${ }^{\circledR}$, previamente tratada..$^{9,11}$ A avaliação desse MEA foi realizada em célula unitária de $25 \mathrm{~cm}^{2}$ da Electrocell, após um período de ativação ${ }^{9}$ de 3,5 h, sendo então obtidos os dados de potencial versus densidade de corrente que permitiram a construção de curvas de polarização dos MEAs (diagramas utilizados para avaliação dos desvios do desempenho de eletrodos em relação ao potencial de equilíbrio). ${ }^{9,11,21}$

O preparo de eletrodos por impressão a tela e os experimentos para determinação da influência das variáveis de impressão na massa de camada catalisadora efetivamente aplicada foram realizados na máquina E1 da Ekra.

O teor de sólidos da tinta foi determinado experimentalmente por diferença de massa entre amostras de tinta colocadas em vidro de relógio antes a após secagem em estufa a $120^{\circ} \mathrm{C}$. Sua densidade foi determinada pela relação entre volume e massas conhecidas.

A viscosidade das tintas foi determinada em viscosímetro Laray, no qual uma haste metálica lubrificada pelo filme de tinta, ao recebe cargas de massas pré-determinadas, desce uma determinada distância em um dado intervalo de tempo, dados esses que permitem o cálculo da taxa de cisalhamento do filme e da viscosidade da mesma.

O tack das tintas foi determinado em Tack-O-Scope B.V. MAV/ EL100 da Test Print. A concentração volumétrica crítica de partículas (CVPC) foi determinada em massa, por meio da adição e mistura de pequenas quantidades de veículo aos sólidos (mistura seca de Nafion e eletrocatalisador) até ser observada uma transição da fluidez da tinta, que passou a apresentar excesso de solvente na sua superfície. ${ }^{16}$

\section{RESULTADOS E DISCUSSÃO}

Os volumes por centímetro quadrado dos tecidos, disponíveis comercialmente, para preparo da matriz de impressão a tela, determinados em função de suas lineaturas estão apresentados na Tabela 2 em $\mathrm{BCM} \mathrm{cm}^{-2}$.

Tabela 2. Relação entre lineatura e volume por centímetro quadrado de tecidos

\begin{tabular}{cc}
\hline Lineatura $\left(\mathrm{cm}^{-1}\right)$ & Volume $\left(\mathrm{BCM} \mathrm{cm}^{-2}\right)$ \\
\hline 15 & 27,2 \\
32 & 12,6 \\
50 & 7,17 \\
77 & 5,24 \\
120 & 2,24 \\
\hline
\end{tabular}

A CVCP da mistura de Nafion e eletrocatalisador em meio ao veículo foi determinada em 34,09\% em massa. Assim, com a intenção de depositar toda a massa de TPCC em apenas uma etapa de aplicação, foi feito o cálculo da massa de sólidos e de veículo a aplicar por $\mathrm{cm}^{2}$ de eletrodo. Inicialmente, considerou-se o depósito de $0,4 \mathrm{mg} \mathrm{Pt} \mathrm{cm}{ }^{-2}$, o que correspondia a 3,077 mg da mistura Nafion/eletrocatalisador, na proporção 35:65. Devido à CVCP a massa mínima do solvente na tinta (a ser aplicada por $\mathrm{cm}^{2}$ de eletrodo) foi calculada em 5,949 g. Com essa informação foi calculado o volume mínimo de solvente $\left(\mathrm{d}=1,036 \mathrm{~g} \mathrm{~cm}^{-3}\right)$ a ser aplicado na tinta por centímetro quadrado, $0,005742 \mathrm{~cm}^{-3}$ ou 5,742 BCM. A tensão superficial do tecido de carbono foi determinada experimentalmente em $32,5 \mathrm{~d} \mathrm{~cm}^{-1} \mathrm{e}$ os valores de tensão dos solventes avaliados estão apresentados na Tabela 3.

Tabela 3. Tensão superficial de alguns solventes

\begin{tabular}{cc}
\hline Solvente & Tensão superficial $\left(\mathrm{d} \mathrm{cm}^{-1}\right)$ \\
\hline n-Hexano & 18,8 \\
Etanol & 26,8 \\
1-Heptanol & 27,6 \\
Etileno glicol & 43,0 \\
Água ultrapura & 71,5 \\
\hline
\end{tabular}

De acordo com a teoria, ${ }^{12}$ a tensão superficial da tinta tem que ser menor que a do substrato de impressão para haver um molhamento adequado no momento da impressão. Assim, dentre os solventes com tensão superficial abaixo de $32,5 \mathrm{~d} \mathrm{~cm}^{-1}$ o 1-heptanol foi escolhido para uso junto com o etileno glicol como veículo na formulação da TPCC, em função de sua baixa pressão de vapor. Após alguns experimentos misturando progressivas quantidades de 1-heptanol ao etileno glicol, foi verificado que 5\% em massa eram suficientes para que o veículo apresentasse uma tensão superficial adequada à aplicação sobre o tecido de carbono.

A densidade e o teor de sólidos em massa da solução aquosa de Nafion ${ }^{\circledR}$ SE10072 são, respectivamente, $1,071 \mathrm{~g} \mathrm{~cm}^{-3}$ e $11,37 \%$. A 
partir da extrapolação linear desses valores (e da densidade da água) foi obtida a densidade teórica de $1,120 \mathrm{~g} \mathrm{~cm}^{-3}$ para os ionômeros de Nafion. A densidade teórica calculada para o eletrocatalisador foi de 4,415 $\mathrm{g} \mathrm{cm}^{-3}$. Essas massas na proporção 35:65 convertidas em volume por centímetro quadrado pelas respectivas densidades resultam em $0,001415 \mathrm{~cm}^{3} \mathrm{~cm}^{-2}$, ou 1,415 $\mathrm{BCM} \mathrm{cm}^{-2}$. Somando os volumes de sólidos e solvente determinados teoricamente chegou-se ao volume de 7,157 BCM de tinta a ser aplicado por $\mathrm{cm}^{2}$. Selecionou-se, então, o tecido com volume de $7,17 \mathrm{BCM} \mathrm{cm}^{-2}$ para o preparo da matriz de impressão e o teor de solventes foi corrigido para esse volume.

Com a TPCC formulada foi obtido o depósito da massa pré-

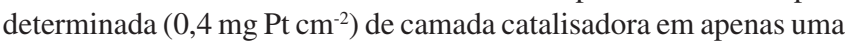
etapa de impressão, usando velocidade de $110 \mathrm{~mm} \mathrm{~min}^{-1}$ e pressão de 1,6 bar. A partir de então, foi realizado um estudo da influência das variáveis de impressão (velocidade e pressão) na massa de tinta transferida. Na Figura 2 é apresentado o diagrama que relaciona a velocidade de impressão com a massa de tinta efetivamente transferida no processo.

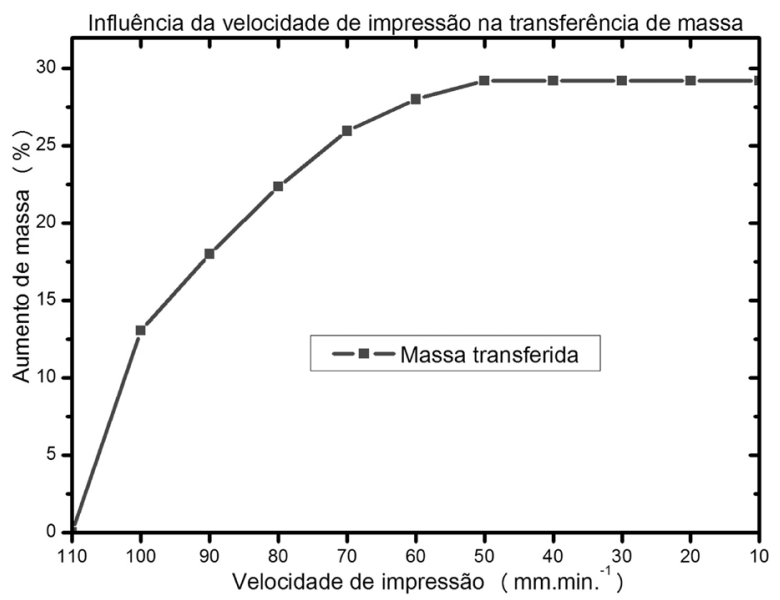

Figura 2. Relação entre a velocidade de impressão e a massa de tinta transferida

Pode-se verificar na Figura 2 que a redução da velocidade de impressão a partir de $110 \mathrm{~mm} \mathrm{~min}^{-1}$ aumenta em até $29 \%$ a massa de tinta transferida por impressão a tela, utilizando a tinta formulada e a matriz com tecido de $501 \mathrm{~cm}^{-1}$. Com isso, uma vez que os âno-

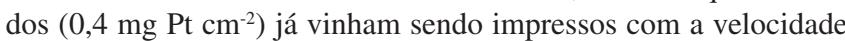
de $110 \mathrm{~mm} \mathrm{~min}^{-1}$, foi verificado que, reduzindo a velocidade para $50 \mathrm{~mm} \mathrm{~min}^{-1}$ a transferência de massa no processo aumentava para o equivalente a $0,52 \mathrm{mg} \mathrm{Pt} \mathrm{cm}{ }^{-2}$. Outros experimentos foram feitos aumentando-se a pressão de impressão com a velocidade de $50 \mathrm{~mm}$ $\min ^{-1}$ e observou-se que a pressão de 1,73 bar resultou no deposito

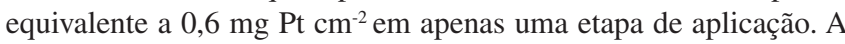
Figura 3 apresenta a influência da pressão de impressão na aplicação da TPCC a $50 \mathrm{~mm} \mathrm{~min}^{-1}$.

Assim, ânodos e cátodos foram impressos em apenas uma etapa de aplicação da tinta formulada por eletrodo, os quais foram usados na confecção de um MEA cujo desempenho é apresentado na Figura 4. A célula unitária foi operada a $75^{\circ} \mathrm{C}$. No ânodo foi utilizado hidrogênio 6.0 analítico, suprido a $90{ }^{\circ} \mathrm{C}$ com fluxo de $355 \mathrm{~mL} \mathrm{~min}{ }^{-1}$ e pressão absoluta de 1 bar. No cátodo foi utilizado oxigênio 4.0 analítico, suprido a $80{ }^{\circ} \mathrm{C}$ com fluxo de $178 \mathrm{~mL} \mathrm{~min}^{-1}$. Em ambos os casos, cátodo e ânodo, os gases reagentes foram saturados com água deionizada (>15 M , Milli-Q), tendo sido obtidas densidades de corrente de até $712 \mathrm{~mA} \mathrm{~cm}^{-2}$ a $0,6 \mathrm{~V}$ com o mesmo.

Após o preparo, a caracterização da tinta foi feita por determinação da densidade, do teor de sólidos, da viscosidade e do tack. Os

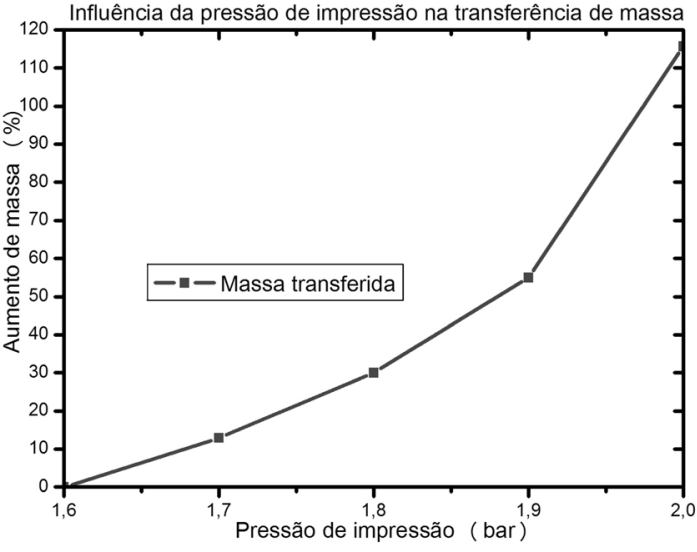

Figura 3. Influência da pressão de impressão na massa de tinta transferida

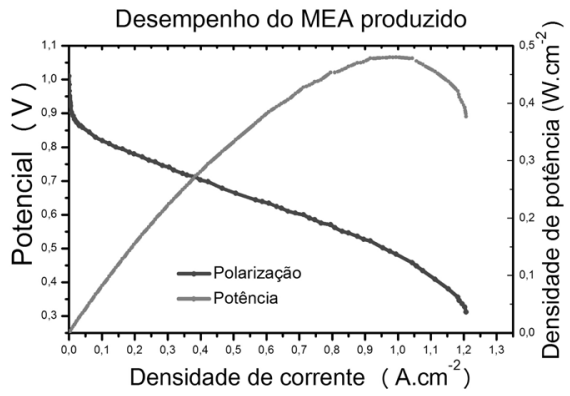

Figura 4. Curvas de polarização e potência do MEA produzido

valores são apresentados na Tabela 4 e comparados com os valores teóricos, sendo que foi considerado valor teórico para viscosidade e para tack os determinados experimentalmente a partir de uma tinta serigráfica comercial (TSC).

Tabela 4. Propriedades da tinta formulada

\begin{tabular}{lccc}
\hline Propriedades da tinta & & & \\
\hline & Teórico & Experimental & Erro \% \\
Densidade $\left(\mathrm{g} \mathrm{cm}^{-3}\right)$ & 1,294 & 1,270 & 1,89 \\
Teor de sólidos (\% em massa) & 33,16 & 33,79 & 1,90 \\
Viscosidade (Pa s) & 2,92 & 2,75 & 5,82 \\
Tack (adimensional) & 55 & 92 & 67,27
\end{tabular}

Com base nos dados da Tabela 4 conclui-se que o processo de mistura e aquecimento dos componentes da TPCC para eliminação dos solventes da solução de Nafion ${ }^{\circledR}$ foi adequado ao preparo da tinta, uma vez que foram obtidos valores experimentais de teor de sólidos e densidade bastante próximos aos teóricos.

Quanto à viscosidade, os valores determinados para a TPCC e para a TSC mostraram-se bastante próximos, o que significa que essa característica da TPCC está adequada ao processo de impressão a tela.

Em relação ao tack, o valor obtido para a TPCC está bastante acima do determinado com a tinta serigráfica comercial, o que significa que a TPCC apresenta maior resistência à separação em camadas que uma tinta comum, indicando que a TPCC dificilmente escorrerá através da tela antes ou após a impressão de eletrodos e que, para seu uso, serão necessárias pressões maiores que as necessárias para uso de uma TSC, como verificado experimentalmente. No entanto, analisando a Figura 5 pode se observar que o tack da tinta serigráfica comercial diminui ao longo do tempo, chegando a zero. Fato que provavelmente ocorreu devido à evaporação dos solventes 
durante a realização do ensaio, em especial entre o $2^{\circ}$ e o $4^{\circ}$ min, fazendo com que a tinta perdesse as interações entre suas camadas, como mencionado.

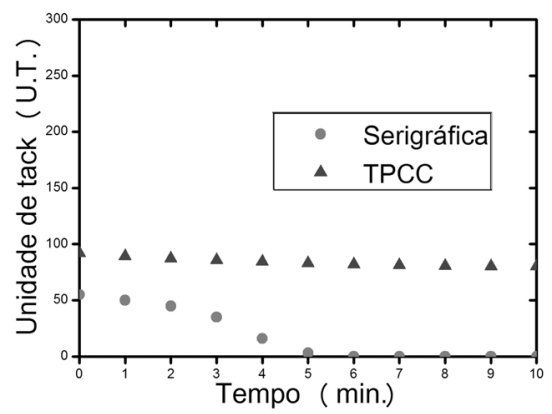

Figura 5. Tack das tintas (TPCC e da TSC) ao longo do tempo

Em contrapartida, o tack da TPCC não apresentou variação significativa ao longo do tempo, não havendo evaporação acentuada de solventes, nem alteração das características da tinta por ação dos esforços realizados em máquina. Essas características demonstraram que o teor de sólidos em massa da TPCC não apresenta alterações significativas em função do tempo, comprovando a estabilidade da tinta desenvolvida.

\section{CONCLUSÕES}

O estudo de tensão superficial foi fundamental para o preparo de uma tinta precursora da camada catalisadora adequada ao processo de impressão a tela para aplicação sobre o tecido de carbono utilizado como camada difusora de gases. Tal aplicação mostrou-se fácil, rápida, reprodutível e evitou a exposição da membrana polimérica a ciclos térmicos antes da prensagem.

As variáveis de processo estudadas permitiram que, com a mesma matriz de impressão e a mesma tinta, fossem realizados, como proposto, o preparo de cátodos e ânodos de células a combustível do tipo PEMFC com as cargas de 0,6 e $0,4 \mathrm{mg} \mathrm{Pt} \mathrm{cm}^{-2}$, respectivamente. Tendo o sistema de impressão a tela sido adequado, satisfatoriamente, à aplicação da TPCC desenvolvida em apenas uma etapa de impressão por eletrodo.

Os MEAs com eletrodos de $25 \mathrm{~cm}^{2}$, preparados em apenas uma etapa de aplicação com a TPCC desenvolvida, apresentaram desempenhos de até $712 \mathrm{~mA} \mathrm{~cm}^{-2}$ na faixa de potencial de operação $(0,6 \mathrm{~V})$.

A tinta precursora da camada catalisadora desenvolvida apresentou todas as características necessárias ao processo de aplicação por impressão a tela. Tendo sido caracterizada por verificação do teor de sólidos pré-determinados e por determinação de densidade, viscosidade e tack, parâmetros que se mostraram suficientes para garantir a reprodutibilidade de preparo e a aplicabilidade da tinta por impressão a tela.
O processo desenvolvido é inovador por ser mais rápido e reprodutível que os divulgados no estado da técnica e permitiu a produção de MEAs em tempo reduzido, contribuindo para uma redução de custos.

\section{AGRADECIMENTOS}

Ao Instituto de Pesquisas Energéticas e Nucleares, IPEN, onde a maior parte do trabalho foi realizado. Escola SENAI Theobaldo de Nigris, nas pessoas de M. J. Cherubine e R. Cuenca, pelo acesso aos laboratórios de caracterização de tintas. Ao CNPq pelo apoio a essa pesquisa, e a Deus pelo transcorrer de tudo.

\section{REFERÊNCIAS}

1. http://www.un.org/esa/population/publications/wpp2008/pressrelease. pdf, acessada em Agosto 2009.

2. Linardi, M.; Economia e energia 2008, 66, 15.

3. Lopes, T.; Gonzalez, E. R.; Quim. Nova 2008, 31, 551.

4. Wendt, H.; Götz, M.; Linardi, M.; Quim. Nova 2000, 23, 538.

5. EG\&G Technical Service, Inc.; Fuel Cell Handbook, U. S. Department of Energy: West Virginia, $7^{\text {th }}$ ed., 2004, cap. 3.

6. Wendt, H.; Linardi, M.; Aricó, E.; Quim. Nova 2002, 25, 470.

7. Kawano,Y.; Wang, Y.; Palmer, R. A.; Polímeros: Ciência e Tecnologia 2002, 12, 96.

8. Perles, C. E.; Polímeros; Ciência e Tecnologia 2008, 18, 281. doi: 10.1590/S0104-14282008000400005.

9. Andrade, A. B.; Bejarano, M. L. M.; Cunha, E. F.; Robalinho, E.; Linardi, M.; J. Fuel Cell Sci. Technol. 2009, 6, 1.

10. Alfenaar, M.; US pat. 4,091,176 1978.

11. Frey, T.; Linardi, M.; Electrochim. Acta 2004, 50, 99.

12. Totsuka, K.; US pat. 6,391,487 2002.

13. Raistrick, I.; US pat. 4,876,115 1989.

14. Zawodzinski, T. A.; Davey, J.; Valerio, J.; Gottesfeld, S.; Electrochim. Acta 1995, 40, 297.

15. Frank, S. N.; Frank, J. G.; US pat. 4,229,490 1980.

16. Fazenda, J. M. R.; Tintas e Vernizes, Ciência e Tecnologia, $3^{\mathrm{a}}$ ed., Edgard Blucher: São Paulo, 2005.

17. Weast, R. C.; Astle, M. J.; Beyer, W. H.; Handbook of Chemistry and Physics, 66 ${ }^{\text {th }}$ ed., CRC: Florida, 1985.

18. Cuenca, R.; Tintas pastosas, $3^{\mathrm{a}}$ ed., SENAI: São Paulo, 2003.

19. Wang, L.; Husar, A.; Zhou, T.; Liu, H.; Int. J. Hydrogen Energy 2003, 28, 1263.

20. Burop, R.; Meyers, J.; Pivovar, B.; Kim, Y. S.; Mukundan, R.; Garland, N.; Myers, D.; Wilson, M.; Garzon, F.; Wood, D.; Zelenay, P.; More, K.; Stroh, K.; Zawodzinski, T.; Boncella, J.; McGrath, J. E.; Inaba, M.; Miyatake, K.; Hori, M.; Ota, K.; Ogumi, Z.; Miyata, S.; Nishikata, A.; Siroma, Z.; Uchimoto, Y.; Yasuda, K.; Kimijima, K.; Iwashita, N.; Chem. Rev. 2007, 107, 3904.

21. Linardi, M.; Introdução à ciência e tecnologia de células a combustível, $1^{a}$ ed., ArtLiber: São Paulo, 2010. 